\title{
Crossing the line: overcoming knowledge boundaries in enterprise transformation
}

Teaser

Enterprise transformations are fundamental changes in an organization. To succeed, shared understanding between many diverse stakeholder groups like program managers or business managers is essential. We analyze which properties of enterprise architecture models are beneficial for creating shared understanding. We assess the differences between stakeholders through the lens of knowledge boundaries, and enterprise architecture models through the lens of boundary objects. We develop and empirically test a research model. Our findings show which boundary object properties contribute to a syntactic, semantic and pragmatic capacity needed to overcome the respective knowledge boundary.

\begin{abstract}
Enterprise transformations are fundamental changes in an organization. Such changes typically affect different stakeholder groups (e.g., program managers, business managers) that exhibit a significant diversity regarding their members' knowledge, goals, and underlying assumptions. Yet, creating shared understanding among diverse stakeholder groups in transformations is a main antecedent for success.

In this paper, we analyze which properties of enterprise architecture models contribute to syntactic, semantic, and pragmatic capacities and thereby help to create shared understanding among stakeholder groups involved in enterprise transformation. We assess the differences among stakeholder groups through the lens of knowledge boundaries, and enterprise architecture models through the lens of boundary objects. We develop and empirically test a research model that describes which boundary object properties are required to overcome three progressively complex knowledge boundaries - syntactic, semantic, and pragmatic.

Our findings show which boundary object properties contribute to a respective capacity needed to overcome each of the three knowledge boundaries. Specifically, we find that for (1) a syntactic capacity, concrete and modular EA models are helpful; (2) a semantic capacity, visual EA model properties are relevant, and (3) a pragmatic capacity, broad stakeholder participation is conductive. Keywords: Boundary objects, Enterprise architecture, Enterprise transformation, Knowledge boundaries, Structural equation modeling
\end{abstract}




\section{Introduction}

Enterprises face an increasing pressure to undergo fundamental change, in other words to transform themselves (Rouse 2005b; Purchase et al. 2011). The causes for such transformation efforts range from internal events like business- or ITdriven initiatives to external events such as the emergence of new technologies or changing regulatory requirements. For this paper, we follow the definition of Rouse (2005b) and refer to changes that fundamentally alter an enterprise's relationship with one of its key constituencies (such as employees, suppliers, customers, or investors) as "enterprise transformation" (ET).

ET affects - in contrast to routine business or small-scale, local change - multiple parts of the organization (Rouse 2005a). The diversity of the affected organizational domains is mirrored in the diversity of the affected stakeholder groups: ET typically is a collaborative endeavor of diverse stakeholders (concerning their knowledge, values, and goals) such as enterprise architects, project/program/portfolio managers, or managers of the affected business units. The need for collaboration among diverse organizational communities is wellrecognized in literature (Carlile 2004; Nicolini et al. 2012; Karsten et al. 2001). To enable and support collaborative efforts during ET, a key success factor is to establish a shared understanding on the current situation, transformation goals, and each other's plans and objectives (Bisel and Barge 2010; Stensaker et al. 2008; Ford and Ford 1995).

To foster shared understanding among stakeholder groups during an ET, one of the major means of communication are models (Frank et al. 2014). To match the diversity of perspectives of stakeholder groups involved in an ET, enterprise architecture (EA) models appear particularly promising: EA models cover dependencies across partial views of an enterprise (e.g., business, technology), and are at a higher level of abstraction than models concerned with partial views. They are of interest to many diverse stakeholder groups because of the holistic overview they provide (Tamm et al. 2011; van der Raadt et al. 2010). 
To better understand how communication can be supported via EA models the concept of boundary objects is used. Boundary objects provide interfaces among different communities of practice (e.g., IT managers and business managers). The boundary object concept has been used in IS literature to analyze the role of IT artifacts, objects, and models for communication among communities of practice (Pawlowski and Robey 2004; Levina and Vaast 2005; Doolin and McLeod 2012; Karsten et al. 2001). The boundary object concept allows to simultaneously regard material properties of EA models and the social context of their use (Doolin and McLeod 2012; Levina and Vaast 2005). Different communities of practice will perceive the quality of a boundary object differently. Therefore, we do not assess specific EA models or model types based on existing quality criteria for conceptual models (e.g., Nelson et al. 2012; Moody 2005; Krogstie et al. 2006; Frank 2014). Instead, we investigate (1) which properties of a boundary object contribute to (2) communication among stakeholder groups that possess a certain degree of difference.

To assess the degree of difference among stakeholder groups, we use the construct of knowledge boundaries. The main assumption is that the differences among groups with regard to their knowledge, values, and goals are manifested in three progressively complex knowledge boundaries: syntactic (information processing), semantic (interpretation), and pragmatic (political) (Carlile 2004). To help to establish shared understanding at the respective knowledge boundary, boundary objects need to have adequate syntactic, semantic, or pragmatic capacities (Rosenkranz et al. 2014).

We formulate our research question accordingly: What are the properties of EA models that enable syntactic, semantic, or pragmatic capacities from a boundary object perspective? To answer this research question, we employ structural equation modeling. We identify EA model properties that have a traceable effect on certain capacities - concrete and modular EA models for a syntactic capacity, visual model properties for a semantic capacity, and models with participation from many communities for a pragmatic capacity. We also point out the 
limitations of EA models by showing when they need to be supplemented by human boundary spanners.

\section{Conceptual Foundations}

\section{Boundary Objects}

Boundary objects are abstract or physical artifacts that support overcoming knowledge boundaries and thus support coordination among different communities of practice by providing common ground. We adopt the definition of Rosenkranz et al. (2014), which builds on the seminal papers on boundary objects: "[b]oundary objects are any 'artifacts, documents, terms, concepts, and other forms of reification around which communities of practice can organize their interconnections' (Wenger, 1998, p. 107). They are 'both plastic enough to adapt to local needs and constraints of the several parties employing them, yet robust enough to maintain a common identity across sites' (Star \& Griesemer, 1989, p. 393)" (Rosenkranz et al. 2014, p. 310).

\section{Enterprise Architecture Models as Boundary Objects}

EA concerns the fundamental structure of an enterprise, as well as the principles guiding its evolution (ISO/IEC/IEEE 2011). EAM aims to shape and develop an EA in a planned and purposeful way, pursuing strategic enterprise goals (Simon et al. 2014) and is considered to support ET (Asfaw et al. 2009; Simon et al. 2013; Labusch and Winter 2013). Central artifact types in EAM are EA models. One benefit is their ability to offer a common frame of reference for diverse stakeholder groups by providing a high-level representation of the basic enterprise structures (Simon et al. 2014; The Open Group 2011; Department of Defense 2012).

Regarding the role of EA models in ET as a facilitator of communication, and the role of boundary objects as communication enablers, it seems promising to conceptualize EA models as boundary objects. Valorinta (2011) indeed finds that EA "possesses many of the characteristics of boundary objects" (Valorinta 2011, p. 50). The boundary object concept motivates the (subsequently confirmed) 
hypothesis that EA is positively related to alignment between IS and business domains. Another application of the boundary object concept to EA is presented by Pareto et al. (2010), who apply the concept to document-based communication (supplementing face-to-face communication) in particularly heterogeneous projects (defined by the "involvement of 1000 people or more" (Pareto et al. 2010, p. 407)).

Smolander et al. (2008) advocate a shift from a blueprint metaphor of architecture, towards a language metaphor. Here, the role of architecture "directly corresponds to the idea of a boundary object" (Smolander et al. 2008, p. 582). This is particularly suitable in ET, where the diversity among communities of practice increases.

The enterprise modeling and conceptual modeling literature also have contributed to describing enterprises from a holistic point. Examples include "Multiperspective enterprise modeling (MEMO)" (Frank 2014), “enterprise ontology” (Dietz and Hoogervorst 2008), or "value modelling" (de Kinderen et al. 2012).

\section{Boundary Object Capacities and Knowledge Boundaries}

The degree of difference among communities of practice in terms of knowledge, goals, and underlying assumptions can be expressed via the construct of knowledge boundaries. "Community of practice" is a term coined by Wenger (2000) to describe a group of people that (1) share a joint area of concern, (2) regularly interact within a set of community-specific norms and relations, and (3) possess a shared repertoire of resources such as languages, methods, tools, stories, or other communal artifacts. ET projects will typically involve multiple communities of practice (Janssen et al. 2013; Doolin and McLeod 2012).

Carlile (2004) distinguishes three types of knowledge boundaries among communities of practice that become increasingly complex to cross: syntactic, semantic, and pragmatic knowledge boundaries. Only after a way has been found to cross these boundaries, knowledge can be transferred, translated, or transformed among the involved communities of practice, resulting in shared 
knowledge. However, before shared knowledge between two communities of practice can be achieved via any of the three aforementioned processes, shared understanding must be established: only when a sufficient "degree of cognitive overlap and commonality in beliefs, expectations, and perceptions about a given target" (Cohen and Gibson 2003, p. 8) is created, can two communities of practice share knowledge. The key argument for shared knowledge to be "always based on shared understanding" (Rosenkranz et al. 2014, pp. 308, emphasis in the original) is that two communities of practice need to first align their "interpretative schemes" (Giddens 1984, p. 29) when they are confronted with a novel situation (like ET). Only after these schemes have been aligned can the communities of practice begin to share knowledge and jointly build new knowledge. In Table 1, we summarize the discussion on knowledge boundaries.

\begin{tabular}{|c|c|c|c|}
\hline & $\begin{array}{l}\text { Syntactic } \\
\text { knowledge } \\
\text { boundary }\end{array}$ & $\begin{array}{l}\text { Semantic } \\
\text { knowledge } \\
\text { boundary }\end{array}$ & $\begin{array}{l}\text { Pragmatic } \\
\text { knowledge } \\
\text { boundary }\end{array}$ \\
\hline $\begin{array}{l}\text { Alternative name: (Knowledge) } \\
\text { Boundary of... }\end{array}$ & $\begin{array}{l}\text { Information } \\
\text { processing }\end{array}$ & Interpretation & Politics \\
\hline $\begin{array}{l}\text { What needs to be developed to } \\
\text { overcome knowledge boundary }\end{array}$ & Common lexicon & $\begin{array}{l}\text { Common } \\
\text { meanings }\end{array}$ & Common interests \\
\hline $\begin{array}{l}\text { Process to share knowledge after } \\
\text { establishment of shared understanding }\end{array}$ & $\begin{array}{l}\text { Knowledge } \\
\text { transfer }\end{array}$ & $\begin{array}{l}\text { Knowledge } \\
\text { translation }\end{array}$ & $\begin{array}{l}\text { Knowledge } \\
\text { transformation }\end{array}$ \\
\hline Boundary object capacity required & $\begin{array}{l}\text { Syntactic } \\
\text { capacity }\end{array}$ & Semantic capacity & Pragmatic capacity \\
\hline Required capacity/capability & $\begin{array}{l}\text { Capacity: } \\
\text { Boundary } \\
\text { objects }\end{array}$ & $\begin{array}{l}\text { Capability: } \\
\text { Boundary objects } \\
\text { (capacity), along } \\
\text { with boundary } \\
\text { spanners' ability }\end{array}$ & $\begin{array}{l}\text { Capability: } \\
\text { Boundary objects } \\
\text { (capacity), along } \\
\text { with boundary } \\
\text { spanners' ability }\end{array}$ \\
\hline
\end{tabular}

Table 1: Knowledge boundary types and associated processes of sharing knowledge (based on Rosenkranz et al. (2014))

Knowledge transfer is concerned with transmitting information from one community of practice to another. A syntactic knowledge boundary exists due to different vocabulary among communities of practice. To create shared understanding at a syntactic knowledge boundary, a common lexicon must be developed (Carlile 2004; Kotlarsky et al. 2012).

Knowledge translation is concerned with making the perspective of one community of practice intelligible to other communities. A semantic knowledge boundary exists when communities of practice attribute different meanings to 
concepts, and have different interpretations of concepts. (Carlile 2004; Hawkins and Rezazade M 2012). To create shared understanding at a semantic knowledge boundary, common meanings must be developed by translating and negotiating among the different meanings of the involved communities.

Knowledge transformation is concerned with altering existing knowledge structures and cognitive frames of communities of practice (Carlile 2004; Boland and Tenkasi 1995). A pragmatic knowledge boundary exists when communities of practice have different interests which affect their ability and willingness to share knowledge. To create shared understanding at a pragmatic knowledge boundary, common interests among the communities of practice must be developed via negotiation processes (Carlile 2004).

Boundary objects are helpful to establish shared understanding at any of these knowledge boundaries. The capacity of the boundary objects, along with the ability of the boundary spanners (i.e., human actors like enterprise architects, who enable communication among different communities like transformation managers or business managers) to use them accordingly, results in a capability to cross a certain knowledge boundary ("capacity x ability = capability" (Rosenkranz et al. 2014, p. 311)).

\section{Research Model}

\section{Model Development}

This paper integrates the results of a cumulative research process. In the first iteration, a structured literature survey has been conducted. 25 articles from leading journals and conferences in the information systems (IS), organizational studies, and general management domains have been analyzed (search term "boundary object*" in title and abstract). The resulting papers have then been scanned for boundary objects and their properties (Abraham 2013), resulting in an initial set of eleven boundary object properties. 
Modularity: Communities can attend to specific areas of a boundary object independently from each other (e.g., attending to individual portions of a roadmap) (Pawlowski and Robey 2004; Star 2010).

Abstraction: A common reference point on a high level of abstraction is provided. Local contingencies are eliminated from high-level views to highlight the commonalities (Levina and Vaast 2005; Gasson 2006).

Concreteness: Specific problems relevant to specific communities are addressed. Communities are able to specify their concerns and express their knowledge related to the problem at hand (Carlile 2002; Pawlowski and Robey 2004).

Shared syntax: A common schema of information elements is provided, so that local use of information objects is uniform across communities (Pawlowski and Robey 2004; Dodgson et al. 2007).

Malleability: Objects are jointly transformable, to support the detection of dependencies and the negotiation of solutions and to provide the involved communities with immediate feedback on how their actions affect each other (Carlile 2004; Doolin and McLeod 2012).

Visualization: Boundary objects do not rely on verbal definitions, but possess a graphical or physical representation (e.g., a drawing or a prototype) (Henderson 1991; Boland and Tenkasi 1995).

Annotation: The boundary object can be enriched with additional information by individual communities in order to provide context for local use (Karsten et al., 2001; Yakura, 2002).

Versioning: Changes to the boundary object are traced and rationales for changes are provided. Additional context can be provided by reconstructing the chronological evolution of the boundary object (Karsten et al., 2001; Mark et al., 2007).

Accessibility: Communities are informed about the boundary object using appropriate communication channels and other measures aimed at helping them to 
use the boundary object, such as trainings (Boland and Tenkasi 1995; Levina 2005).

Up-to-dateness: The boundary object is continuously updated, and changes are communicated in a timely fashion to the involved communities (Carlile 2002; Karsten et al. 2001).

Stability: The structure of a boundary object remains stable over time. While changes at the periphery are possible, the core of the boundary object remains stable and recognizable (Yakura 2002; Karsten et al. 2001).

The literature perspective has been complemented with a practitioner view by conducting a focus group. The focus group panelists (nine enterprise architects) were drawn from German and Swiss enterprises (mainly from the financial services and electric utility industries) and had several years of experience in the fields of EA, data architecture, IT architecture, or IT strategy (Abraham 2013). The focus group proposed an additional property (participation).

Participation: Communities are involved in the creation and maintenance of the boundary object. The boundary object should also be used by top management.

Then, an initial set of hypotheses has been constructed mapping the boundary object properties to syntactic, semantic, or pragmatic capacities. To further explore this mapping empirically, we conducted a series of expert interviews with twelve enterprise architects (a different panel than the focus group described above) (Abraham et al. 2013). Each interview took between 60 and 90 minutes. We coded the interview transcripts to identify occurrences of knowledge boundaries, the use of boundary objects, for example EA to-be models or EA roadmaps, and the role of enterprise architects as boundary spanners.

After reflecting the findings from the interviews and the feedback from the conference audience (Abraham et al. 2013), and after revisiting the literature on boundary objects and knowledge boundaries (e.g., Kotlarsky et al. 2012; Carlile 2004; Hawkins and Rezazade M 2012), we build and test our final research model. 


\section{Model Description}

The research model has two blocks: the boundary object properties, and the capacities they influence. Our unit of analysis is EA models as boundary objects. The level of analysis is the inter-group level (the capacity of EA models as boundary objects to overcome knowledge boundaries among different communities of practice). Figure 1 shows the research model.

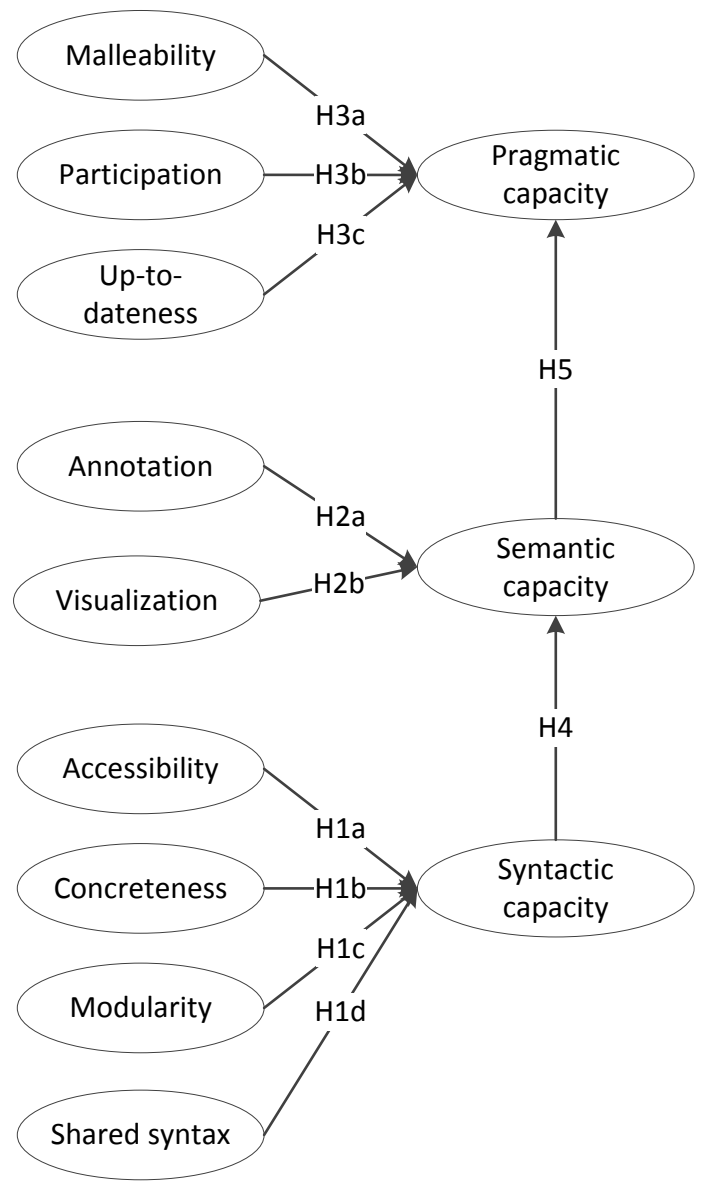

Figure 1: Research model: boundary object properties' contribution to model capacities

The left part in the research model describes the boundary object properties as independent variables supporting one of the three capacities.

Accessibility . By using appropriate communication channels, members of different communities of practice can be familiarized with the boundary object. Explicating community knowledge, and making it accessible to others, helps to establish a common syntax (Boland and Tenkasi 1995; Smolander et al. 2008). 
Concreteness. Boundary objects that provide communities of practice with a concrete reference point (e.g., boundary objects that adhere to an industry-wide defined standard) are found to be beneficial for establishing a common syntax (Bechky 2003; Barley et al. 2012).

Modularity. Pareto et al. (2010, p. 415) call for filtering components that remove parts of the model on demand. By allowing different communities to attend to different parts of the same boundary object, knowledge about each community's terms and syntax is transferred back and forth (Boland and Tenkasi 1995).

Shared syntax is frequently associated in literature (Carlile 2002; Kellogg et al. 2006) with overcoming syntactic knowledge boundaries.

We formulate our hypotheses as follows:

- H1a: Accessibility increases the syntactic capacity of boundary objects.

- H1b: Concreteness increases the syntactic capacity of boundary objects.

- H1c: Modularity increases the syntactic capacity of boundary objects.

- H1d: Shared syntax increases the syntactic capacity of boundary objects.

Annotation is hypothesized to contribute to a semantic capacity, by allowing to uncover and consolidate different meanings (Yakura 2002; Pareto et al. 2010).

Visualization. A cognitively efficient visual notation is considered beneficial for detecting differences and dependencies in interpretation. Henderson (1991) finds that using sketches and diagrams facilitates the reading of alternative meanings among groups of engineers. Boland and Tenkasi (1995) argue that visual representations (e.g., conceptual models) support a sense-making rather than a problem-solving process. Therefore, we associate visualization with a semantic rather than a pragmatic capacity.

We formulate our hypotheses as follows:

- H2a: Annotation increases the semantic capacity of boundary objects.

- H2b: Visualization increases the semantic capacity of boundary objects. 
Malleability is frequently mentioned in literature to support overcoming pragmatic boundaries (Carlile 2004; Doolin and McLeod 2012). A jointly transformable object helps different communities to try out solution alternatives and negotiate a common solution.

Participation. When communities of practice actively participate in creating, editing and maintaining the boundary object, this object is likely to enjoy higher acceptance than a "designated boundary object" (Levina and Vaast 2005). Moreover, the involved communities of practice participate in the solution negotiation process.

Up-to-dateness. Improvisation is a key aspect when members of different communities discuss solutions to address novel conditions. The availability of upto-date information is an important enabler of improvisation (Vera and Crossan 2005). Conversely, when outdated information is provided, this could be interpreted as dishonest communication (Abraham et al. 2013).

We formulate our hypotheses as follows:

- H3a: Malleability increases the pragmatic capacity of boundary objects.

- H3b: Participation increases the pragmatic capacity of boundary objects.

- H3c: Up-to-dateness increases the pragmatic capacity of boundary objects.

We model concreteness as an individual construct at a syntactic knowledge boundary, since this property is hypothesized to be required for knowledge transfer. We refrain from modeling abstraction as an individual construct at the semantic knowledge boundary, but rather see it as a facet of the visualization property: Models on a high level of problem description aid knowledge translation, whereas models on a detailed level of problem description aid knowledge transfer by exposing community-specific terminology (Parsons 2003). The interlinking among different levels of problem description is part of an efficient visualization, by allowing navigation through different problem description layers (cf. Moody's (2009) design principle of complexity management). 
The right part of the research model shows the three capacities that can be enabled in boundary objects — syntactic, semantic, and pragmatic capacities. By modeling an increase in complexity from a syntactic over a semantic to a pragmatic knowledge boundary, our research model is consistent with Carlile $(2004,2002)$ and Rosenkranz et al. (2014).

We formulate our hypotheses as follows:

- H4: An increase of the syntactic capacity of a boundary object leads to an increase of the semantic capacity.

- H5: An increase of the semantic capacity of a boundary object leads to an increase of the pragmatic capacity.

\section{Research Method}

\section{Construct Operationalization}

The necessary measurement items are derived from literature, construct definitions, and expert suggestions (MacKenzie et al. 2011). In operationalizing our constructs, we strive for reuse of existing measurement instruments which describe critical success factors and are supported by either theoretical arguments or empirical data. However, some items are directly derived from the boundary object property definitions, as there are few works in literature dealing with the exact properties of boundary objects, specifically when applied to EA models. The selection of the items and the wording of the questionnaire have been discussed over four iterations within the author team and with other colleagues (Urbach and Ahlemann 2010). The result of this discussion process is our final set of construct indicators (see Appendix A). We show where existing items could be adopted, have been newly developed, or have been dropped (when they could not be unambiguously attributed to a single construct).

\section{Sample Description}

To test our hypotheses, we follow a quantitative empirical approach. We conduct a survey among EA academics and practitioners using a questionnaire. The 
questionnaire was distributed on six occasions in German and English language and yielded $\mathrm{n}=111$ fully completed and usable questionnaires. See Appendices B and $\mathrm{C}$ for details on the questionnaire and the distribution occasions.

All respondents were actively engaged in EAM either professionally or academically. At all events, academics, and consultants have been instructed to answer the questionnaire from the perspective of the industry project they were most familiar with. All participants were asked to answer the questions on model use and model properties from the perspective of one particular model they considered most likely to support communication among different communities. Since we are interested in a broad coverage of the specific aspect of the modelsthe degree to which certain of their properties influenced certain capacities - the heterogeneity of the model instances reported in this survey is a deliberate choice (see Appendix D for an overview on the model types reported by our respondents).

Performing analyses of variance on our sample, we did not find company size, EAM, or ET experience level to have significant effects on our results, which is in line with comparable studies in IS development (Aier et al. 2011a; Aier et al. 2011b). We also no not expect geography or industry to have significant effects on our results.

The research model has been transformed into a structural equation model and tested using a partial least squares (PLS) approach (we use SmartPLS (Ringle et al. 2005), version 2.0.M3). We have used a case-wise replacement algorithm to deal with missing values. With regard to our research purpose, we favor the PLS approach. PLS has less strict distributional assumptions and is more suitable for the exploration of relationships (this is particularly relevant, since our paper is among the first to explore EA through the boundary object lens at the level of individual properties). Moreover, PLS has a lower sample size requirement. According to Chin et al. (2003), the sample size for PLS should be at least ten times the maximum number of predictor variables for a construct. In our case, this number is four (for the "syntactic capacity" construct). The resulting threshold of 
40 is met by our sample size of 111 . However, given the weak to moderate effect sizes in our model, our sample size is still near the minimum required sample size. The stability of the estimates has been assessed using the boot-strapping resampling procedure with 5000 resamples (Hair Jr et al. 2011, p. 145). Significances have been determined by means of two-tailed t-tests.

\section{Model Evaluation}

The evaluation of the measurement model and the structural model follows the procedures outlined by Chin (2010) and Götz et al. (2010). See Appendix E for the numerical results of the model evaluation. All constructs have been measured in reflective mode. The measurement model is evaluated for the following criteria: (1) content validity, (2) indicator reliability, (3) construct reliability, (4) convergent validity, and (5) discriminant validity.

Content validity has to be ensured a priori through theoretical considerations, namely that the measurement model (qualitatively) represents the conceptual domain of the construct in question. This was done based on the previous research steps and the theoretical considerations outlined earlier.

Indicator reliability specifies which part of an indicator's variance can be explained by the underlying latent variable. The factor loadings $\lambda$ should be larger than 0.7, which is the case for all indicators except MAL1 (0.69).

Construct reliability indicates how well all indicators taken together measure their respective construct. This can be measured via the composite reliability (CR) or Cronbach's alpha (CA) criterion (CA assumes equal weightings; since we do not assume equal weightings among the facets that are captured by the indicators of a construct, $\mathrm{CR}$ is more adequate in our case). For both CA and CR, values should be larger than 0.6. In our case, CR is always above these thresholds. CA is below this threshold for one construct (MAL at 0.44) and meets this threshold for another construct (SYN at 0.60).

Convergent validity is assessed with the average variance extracted (AVE) measure. AVE should be larger than 0.5, meaning that a greater part of the 
construct's variance is explained by its indicator than by the error term. In our model, this is the case. Still, for the syntactic capacity construct, both AVE and CA values are very close to the recommended minimum threshold.

Discriminant validity is about the dissimilarity of the constructs - in other words, whether the indicators load only to their own construct and not to others. According to the Fornell-Larcker-criterion (Fornell and Larcker 1981), discriminant validity is given if the square root of a latent variable's AVE is larger than the common variances (correlations) of this latent variable with any other of the model's constructs. This holds true for all our measurement constructs.

\section{Model Results}

The model evaluation shows that eight out of ten hypotheses hold (see Table 2). We assess the significance of our hypotheses via a two-tailed t-test. The R-square values of $0.448,0.331$, and 0.398 for syntactic, semantic, and pragmatic capacities of boundary objects show that the associated boundary object properties account for between $33 \%$ and $45 \%$ of the variance in the capacities. While there are no universal recommendations on acceptable values for R-square (Chin 1998b, a), we consider this to be a reasonable value, given the complexity of our model.

\begin{tabular}{|c|c|c|c|c|}
\hline $\begin{array}{l}\text { Hypo- } \\
\text { thesis }\end{array}$ & $\begin{array}{l}\text { Path } \\
\text { description }\end{array}$ & $\begin{array}{l}\text { Path coefficient, } \\
\text { significance }\end{array}$ & t-score & Result \\
\hline H1a & $\begin{array}{l}\text { Accessibility } \rightarrow \text { Syntactic } \\
\text { capacity }\end{array}$ & 0.022 & 0.349 & Not Supported \\
\hline $\mathrm{H} 1 \mathrm{~b}$ & $\begin{array}{l}\text { Concreteness } \rightarrow \text { Syntactic } \\
\text { capacity }\end{array}$ & 0.380 & $4.162 * * * *$ & Supported \\
\hline $\mathrm{H} 1 \mathrm{c}$ & $\begin{array}{l}\text { Modularity } \rightarrow \text { Syntactic } \\
\text { capacity }\end{array}$ & 0.201 & $2.137 * *$ & Supported \\
\hline H1d & $\begin{array}{l}\text { Shared Syntax } \rightarrow \text { Syntactic } \\
\text { capacity }\end{array}$ & 0.243 & $2.491 * *$ & Supported \\
\hline $\mathrm{H} 2 \mathrm{a}$ & $\begin{array}{l}\text { Annotation } \rightarrow \text { Semantic } \\
\text { capacity }\end{array}$ & 0.314 & $3.222 * * *$ & Supported \\
\hline $\mathrm{H} 2 \mathrm{~b}$ & $\begin{array}{l}\text { Visualization } \rightarrow \text { Semantic } \\
\text { capacity }\end{array}$ & 0.280 & $3.698 * * * *$ & Supported \\
\hline $\mathrm{H} 3 \mathrm{a}$ & $\begin{array}{l}\text { Malleability } \rightarrow \text { Pragmatic } \\
\text { capacity }\end{array}$ & 0.246 & $3.148 * * *$ & Supported \\
\hline $\mathrm{H} 3 \mathrm{~b}$ & $\begin{array}{l}\text { Participation } \rightarrow \text { Pragmatic } \\
\text { capacity }\end{array}$ & 0.160 & $1.722^{*}$ & Supported \\
\hline $\mathrm{H} 3 \mathrm{c}$ & Up-to-dateness $\rightarrow$ & -0.136 & 1.561 & Not Supported \\
\hline
\end{tabular}




\begin{tabular}{|l|l|l|l|l|}
\hline & Pragmatic capacity & & & \\
\hline H4 & $\begin{array}{l}\text { Syntactic capacity } \rightarrow \\
\text { Semantic capacity }\end{array}$ & 0.189 & $1.871 *$ & Supported \\
\hline H5 & $\begin{array}{l}\text { Semantic capacity } \rightarrow \\
\text { Pragmatic capacity }\end{array}$ & 0.470 & $5.754 * * * *$ & Supported \\
\hline & \multicolumn{3}{|c|}{ Legend: ****: $\alpha<0.001 ; * * *: \alpha<0.01 ; * *: \alpha<0.05 ; *: \alpha<0.1 ;$} \\
\hline
\end{tabular}

Table 2: Results of PLS path analysis

\section{Discussion}

\section{Findings}

This study contributes original insights for three reasons: First, it is one of the first studies to follow the calls in literature (Smolander et al. 2008; Valorinta 2011) to apply the boundary object concept to EAM at a specific level: our unit of analysis is an individual EA model at the inter-group level. Second, we break down the construct of boundary objects into individual properties and differentiate among three progressively complex capacities, providing design guidelines for subsequent EA model development. Third, our results shed light on the transition between the capacities of EA models, and the required abilities of enterprise architects: where are the capacities of models sufficient, and where are the abilities of enterprise architects central?

Regarding the results of the model evaluation, the properties of concreteness and visualization appear to have particular importance for syntactic and semantic capacities, being significant at the 0.001 level. For the design of boundary objects, these findings imply the importance of (1) an object that is connected to the concrete domains (i.e., universes of discourse) of the involved communities, and that (2) possesses a cognitively efficient visual notation. Interestingly, the two hypotheses that are not supported by the data are both concerned with properties that address the use and management of EA models rather than their construction - up-to-dateness and accessibility. An explanation for the lacking support of accessibility for a syntactic capacity might be that boundary objects emerge from the communities' work practices, and can only be partly pre- 
designed (Landry et al. 2009). The low empirical support for up-to-dateness indicates that this property does not contribute significantly to a pragmatic capacity of boundary objects. A potential explanation may be that up-to-dateness is not a capacity-enabling property, but rather an essential requirement towards any model.

The connection between a semantic and a pragmatic capacity (H5) is significant at the 0.001 level, whereas the connection between a syntactic and a semantic capacity (H4) is only significant at the 0.1 level. On the other hand, the explained variance (R-square) is highest for syntactic capacities. This is in line with the findings of Rosenkranz et al. (2014) that boundary objects are sufficient to create shared understanding at syntactic knowledge boundaries, but need to be supplemented by boundary spanners at semantic and pragmatic knowledge boundaries. Moreover, the results show that a pragmatic capacity depends strongly on the prior establishment of a semantic capacity.

\section{Limitations}

Some limitations must be discussed before implications for either research or practice can be derived. First, our sample is not representative, since it focuses only on enterprise architects. While the selection of this particular community seems natural in connection with EA models, the results in this work must be interpreted accordingly. Further iterations should also consider communities like transformation managers, business managers, or program managers. In a similar vein, we did not restrict the possible answers to a specific ET scenario. However, since our primary audience are enterprise architects, we expect this group to be actively involved in ET projects, given the role of architectural support in ET.

Second, the research model requires more in-depth testing, as it presents a novel and more fine-grained perspective on EA models by breaking down the boundary objects construct into a set of EA model properties. We could only adopt few measurement items from literature, had to adapt some, and had to create new scales for several constructs. 
Third, the responses collected in our survey relate to different models (see Appendix D) used by different communities of practice. The findings of this research are therefore not attributable to a specific model type used among specific communities of practice. This research must be seen as a first exploration into model properties that enable certain capacities. Further research is required to refine the results in specific model types.

Finally, we are aware that additional context factors influence shared understanding in ET. A particularly interesting context factor is the power relationships among the involved communities of practice (Barrett and Oborn 2010). In the case of a particularly lopsided power distribution, a powerful community of practice might simply force its perspective on others, instead of fostering shared understanding via boundary objects.

\section{Implications for Research and Practice}

Being aware of these limitations, we nevertheless consider the boundary object lens beneficial to address the idiosyncrasies of our object of inquiry-EA models in ET. Recently published research agendas in this journal recognize the impact of stakeholder divergence on model development and call for approaches "that are suited to address the inherent divergences and the resulting frictions effectively" (Frank et al. 2014, p. 39). We consider the adherence to boundary object properties as requirements for EA model design as a contribution to meeting this challenge.

The identified properties address both material aspects of EA models (e.g., modularity), as well as the way they are embedded in a social context (e.g., participation). This integral approach is central to the boundary objects perspective of EA models: EA models become boundary objects only during their (Levina and Vaast 2005), yet this focus must not lead to neglecting the material properties of EA models. The mapping of boundary object properties to syntactic, semantic, and pragmatic capacities can provide indications to researchers which existing EA models might work as boundary objects in situations where certain capacities are required. 
For researchers following a behavioristic research paradigm, the effect of boundary objects in actual ET may be observed in future studies, for example on the mutual influence of boundary objects and their application context in ET: how boundary objects shape ET (enable the transfer, translation, and transformation of knowledge), and how they are at the same time shaped by ET (i.e., how their capacities change when they get adopted or even adapted by new communities of practice). A sociomaterial perspective (Orlikowski and Scott 2008) provides a suitable lens for such investigations. For researchers following a design science research paradigm, this research is a first step towards developing design principles for boundary objects by indicating which properties to focus on when a certain capacity is desired.

For practitioners, finally, the results of this research can predict which boundary objects are effective when a certain capacity is required. Decisions could then be made to either invest in a certain capacity (e.g., invest in a syntactic capacity to free boundary spanner resources from establishing shared understanding when a comparatively easy syntactic knowledge boundary is faced), or to improve the tool set of boundary spanners at semantic or pragmatic knowledge boundaries.

\section{Conclusion}

Motivated by the need for shared understanding among diverse communities of practice in ET, we have formulated our research question: What are the properties of EA models that enable syntactic, semantic, or pragmatic capacities from a boundary object perspective? We have developed a research model and tested it using PLS with a data set of 111 questionnaires collected from enterprise architects. Our findings confirm the majority of the postulated hypotheses by showing which boundary object properties are required in the presence of which knowledge boundary. We discuss implications for theory, particularly taking into account postulated research agendas for modeling IS, and formulate initial action guidelines for practitioners. 


\section{Acknowledgements}

This work has been supported by the Swiss National Science Foundation (SNSF).

\section{References}

Abraham R (2013) Enterprise Architecture Artifacts as Boundary Objects - A Framework of Properties. In: ECIS 2013 Completed Research, Paper 120

Abraham R, Niemietz H, de Kinderen S, Aier S (2013) Can boundary objects mitigate communication defects in enterprise transformation? Findings from expert interviews. In:

Proceedings of the 5th International Workshop on Enterprise Modelling and Information Systems Architectures (EMISA 2013), pp 27-40

Aier S, Bucher T, Winter R (2011a) Critical Success Factors of Service Orientation in Information Systems Engineering - Derivation and Empirical Evaluation of a Causal Model. Business \& Information Systems Engineering 3(2):77-88

Aier S, Gleichauf B, Winter R (2011b) Understanding Enterprise Architecture Management Design - An Empirical Analysis. In: Wirtschaftsinformatik Proceedings 2011, Paper 50

Asfaw T, Bada A, Allario F (2009) Enablers and Challenges in Using Enterprise Architecture Concepts to Drive Transformation: Perspectives from Private Organizations and Federal Government Agencies. Journal of Enterprise Architecture 5(3):18-28

Barley WC, Leonardi PM, Bailey DE (2012) Engineering Objects for Collaboration: Strategies of Ambiguity and Clarity at Knowledge Boundaries. Human Communication Research 38(3):280308

Barrett M, Oborn E (2010) Boundary object use in cross-cultural software development teams. Human Relations 63(8):1199-1221

Bechky BA (2003) Sharing Meaning across Occupational Communities: The Transformation of Understanding on a Production Floor. Organization Science 14(3):312-330

Bisel RS, Barge JK (2010) Discursive positioning and planned change in organizations. Human Relations 64(2):257-283

Boland RJ, Tenkasi RV (1995) Perspective Making and Perspective Taking in Communities of Knowing. Organization Science 6(4):350-372

Carlile PR (2002) A Pragmatic View of Knowledge and Boundaries: Boundary Objects in New Product Development. Organization Science 13(4):442-455

Carlile PR (2004) Transferring, Translating, and Transforming: An Integrative Framework for Managing Knowledge Across Boundaries. Organization Science 15(5):555-568 
Chin WW (1998a) Issues and Opinion on Structural Equation Modeling. MIS Quarterly 22(1):viiXvi

Chin WW (1998b) The Partial Least Squares Approach to Structural Equation Modeling. In: Marcoulides GA (ed) Modern Methods for Business Research. Lawrence Erlbaum Associates, Mahwah, NJ, USA, pp 295-336

Chin WW (2010) How to Write Up and Report PLS Analyses. In: Vinzi VE, Chin WW, Henseler J, Wang H (eds) Handbook of Partial Least Squares. Concepts, Methods and Applications. Springer, Berlin, Heidelberg, Germany, pp 655-690

Chin WW, Marcolin BL, Newsted PR (2003) A Partial Least Squares Latent Variable Modeling Approach for Measuring Interaction Effects: Results from a Monte Carlo Simulation Study and an Electronic-Mail Emotion/Adoption Study. Information Systems Research 14(2):189-217 Cohen SG, Gibson CB (2003) In the beginning: Introduction and framework. In: Cohen SG, Gibson CB (eds) Virtual teams that work: Creating conditions for virtual team effectiveness. Jossey-Bass, San Francisco, CA, USA, pp 1-14

de Kinderen S, Gaaloul K, Proper HA (2012) Integrating Value Modelling into ArchiMate. In: Proceedings of the Third International Conference on Exploring Service Science, pp 125-139 Department of Defense (2012) DoD Architecture Framework Version 2.02. http://dodcio.defense.gov/TodayinCIO/DoDArchitectureFramework.aspx. Accessed 30.09.2014 Dietz JLG, Hoogervorst JAP (2008) Enterprise Ontology in Enterprise Engineering. In: Proceedings of the 2008 ACM Symposium on Applied Computing, pp 572-579

Dodgson M, Gann DM, Salter A (2007) “In Case of Fire, Please Use the Elevator": Simulation Technology and Organization in Fire Engineering. Organization Science 18(5):849-864

Doolin B, McLeod L (2012) Sociomateriality and boundary objects in information systems development. European Journal of Information Systems 21(5):570-586

Ford JD, Ford LW (1995) The role of conversations in producing intentional change in organizations. The Academy of Management Review 20(3):541-570

Fornell C, Larcker DF (1981) Evaluating structural equation models with unobservable variables and measurement error. Journal of Marketing Research 18(1):39-50

Frank U (2014) Multi-perspective enterprise modeling: foundational concepts, prospects and future research challenges. Software \& Systems Modeling 13(3):941-962

Frank U, Strecker S, Fettke P, Brocke J, Becker J, Sinz E (2014) The Research Field "Modeling Business Information Systems”. Business \& Information Systems Engineering 6(1):39-43

Gasson S (2006) A genealogical study of boundary-spanning IS design. European Journal of Information Systems 15(1):26-41 
Giddens A (1984) The constitution of society: Outline of theory of structuration. University of California Press, Berkeley, CA, USA

Götz O, Liehr-Gobbers K, Krafft M (2010) Evaluation of Structural Equation Models Using the Partial Least Squares (PLS) Approach. In: Vinzi VE, Chin WW, Henseler J, Wang H (eds)

Handbook of Partial Least Squares: Concepts, Methods and Applications. 1 edn. Springer, Berlin, Heidelberg, Germany, pp 691-711

Hair Jr JF, Ringle CM, Sarstedt M (2011) PLS-SEM: Indeed a Silver Bullet. Journal of Marketing Theory and Practice 19(2):139-151

Hawkins MA, Rezazade M MH (2012) Knowledge boundary spanning process: synthesizing four spanning mechanisms. Management Decision 50(10):1800-1815

Henderson K (1991) Flexible Sketches and Inflexible Data Bases: Visual Communication, Conscription Devices, and Boundary Objects in Design Engineering. Science, Technology, \& Human Values 16(4):448-473

ISO/IEC/IEEE (2011) Systems and software engineering — Architecture description (ISO/IEC/IEEE 42010:2011).

Janssen M, Veenstra A, Voort H (2013) Management and Failure of Large Transformation Projects: Factors Affecting User Adoption. In: Dwivedi Y, Henriksen H, Wastell D, De’ R (eds) Grand Successes and Failures in IT. Public and Private Sectors. Springer, Berlin, Heidelberg, Germany, pp 121-135

Karsten H, Lyytinen K, Hurskainen M, Koskelainen T (2001) Crossing boundaries and conscripting participation: representing and integrating knowledge in a paper machinery project. European Journal of Information Systems 10(2):89-98

Kellogg KC, Orlikowski WJ, Yates J (2006) Life in the Trading Zone: Structuring Coordination Across Boundaries in Postbureaucratic Organizations. Organization Science 17(1):22-44

Kotlarsky J, Hooff Bvd, Huysman M (2009) Bridging Knowledge Boundaries in Cross- Functional Groups: The Role of a Transactive Memory System. In: ICIS 2009 Proceedings, Paper 1

Kotlarsky J, van den Hooff B, Houtman L (2012) Are We on the Same Page? Knowledge Boundaries and Transactive Memory System Development in Cross-Functional Teams. Communication Research Advance online publication(doi: 10.1177/0093650212469402)

Krogstie J, Sindre G, Jørgensen H (2006) Process models representing knowledge for action: a revised quality framework. European Journal of Information Systems 15(1):91-102

Labusch N, Winter R (2013) Towards a Conceptualization of Architectural Support for Enterprise Transformation. In: ECIS 2013 Completed Research, Paper 116 
Landry SJ, Levin K, Rowe D, Nickelson M (2009) Enabling Collaborative Work Across Different Communities of Practice Through Boundary Objects: Field Studies in Air Traffic Management. International Journal of Human-Computer Interaction 26(1):75-93

Levina N (2005) Collaborating on Multiparty Information Systems Development Projects: A Collective Reflection-in-Action View. Information Systems Research 16(2):109-130

Levina N, Vaast E (2005) The Emergence of Boundary Spanning Competence in Practice: Implications for Implementation and Use of Information Systems. MIS Quarterly 29(2):335-363

MacKenzie SB, Podsakoff PM, Podsakoff NP (2011) Construct Measurement and Validation Procedures in MIS and Behavioral Research: Integrating New and Existing Techniques. MIS Quarterly 35(2):293-334

Moody DL (2005) Theoretical and practical issues in evaluating the quality of conceptual models: current state and future directions. Data \& Knowledge Engineering 55(3):243-276

Moody DL (2009) The "Physics" of Notations: Toward a Scientific Basis for Constructing Visual Notations in Software Engineering. IEEE Transactions on Software Engineering 35(5):756-778

Nelson JH, Poels G, Genero M, Piattini M (2012) A conceptual modeling quality framework. Journal of Software Quality Control 20(1):201-228

Nicolini D, Mengis J, Swan J (2012) Understanding the Role of Objects in Cross-Disciplinary Collaboration. Organization Science 23(3):612-629

Orlikowski WJ, Scott SV (2008) 10 Sociomateriality: Challenging the Separation of Technology, Work and Organization. The Academy of Management Annals 2(1):433-474

Østerlund C (2008) The Materiality of Communicative Practices. Scandinavian Journal of Information Systems 20(1):7-40

Pareto L, Eriksson P, Ehnebom S (2010) Architectural Descriptions as Boundary Objects in System and Design Work. In: Petriu DC, Rouquette N, Haugen $\varnothing$ (eds) Model Driven Engineering Languages and Systems. Springer, Berlin, Heidelberg, Germany, pp 406-419

Parsons J (2003) Effects of Local Versus Global Schema Diagrams on Verification and Communication in Conceptual Data Modeling. Journal of Management Information Systems 19(3):155-183

Pawlowski SD, Robey D (2004) Bridging User Organizations: Knowledge Brokering and the Work of Information Technology Professionals. MIS Quarterly 28(4):645-672

Preston DS, Karahanna E (2009) Antecedents of IS Strategic Alignment: A Nomological Network. Information Systems Research 20(2):159-179 
Purchase V, Parry G, Valerdi R, Nightingale D, Mills J (2011) Enterprise Transformation: Why Are We Interested, What Is It, and What Are the Challenges? Journal of Enterprise Transformation $1(1): 14-33$

Rehm S-V, Goel L (2013) Composite Boundary Objects In Inter-Organizational Innovation Activities. In: ECIS 2013 Completed Research, Paper 7

Ringle CM, Wende S, Will A (2005) SmartPLS 2.0 (beta). University of Hamburg, Hamburg, Germany

Rosenkranz C, Vraneši H, Holten R (2014) Boundary Interactions and Motors of Change in Requirements Elicitation: A Dynamic Perspective on Knowledge Sharing. Journal of the Association for Information Systems 15(6):306-345

Rouse WB (2005a) Enterprises as systems: Essential challenges and approaches to transformation. Systems Engineering 8(2):138-150

Rouse WB (2005b) A Theory of Enterprise Transformation. Systems Engineering 8(4):279-295

Schmidt C, Buxmann P (2011) Outcomes and success factors of enterprise IT architecture management: empirical insight from the international financial services industry. European Journal of Information Systems 20(2):168-185

Simon D, Fischbach K, Schoder D (2013) An Exploration of Enterprise Architecture Research. Communications of the Association for Information Systems 32(1):1-72

Simon D, Fischbach K, Schoder D (2014) Enterprise architecture management and its role in corporate strategic management. Information Systems and e-Business Management 12(1):5-42 Smolander K, Rossi M, Purao S (2008) Software architectures: blueprint, literature, language or decision? European Journal of Information Systems 17(6):575-588

Star SL (2010) This is Not a Boundary Object: Reflections on the Origin of a Concept. Science, Technology, \& Human Values 35(5):601-617

Stensaker I, Falkenberg J, Grønhaug K (2008) Implementation Activities and Organizational Sensemaking. The Journal of Applied Behavioral Science 44(2):162-185

Tamm T, Seddon PB, Shanks G, Reynolds P (2011) How Does Enterprise Architecture Add Value to Organisations? Communications of the Association for Information Systems 28(1):141-168

The Open Group (2011) TOGAF Version 9.1. The Open Group,

Urbach N, Ahlemann F (2010) Structural Equation Modeling in Information Systems Research Using Partial Least Squares. Journal of Information Technology Theory and Application 11(2):540 
Valorinta M (2011) IT alignment and the boundaries of the IT function. Journal of Information Technology 26(1):46-59

van der Raadt B, Bonnet M, Schouten S, van Vliet H (2010) The relation between EA

effectiveness and stakeholder satisfaction. Journal of Systems and Software 83(10):1954-1969

Vera D, Crossan M (2005) Improvisation and Innovative Performance in Teams. Organization

Science 16(3):203-224

Wenger E (2000) Communities of Practice and Social Learning Systems. Organization 7(2):225246

Winter SJ, Butler BS (2011) Creating bigger problems: grand challenges as boundary objects and the legitimacy of the information systems field. Journal of Information Technology 26(2):99-108 Yakura EK (2002) Charting Time: Timelines as Temporal Boundary Objects. The Academy of Management Journal 45(5):956-970 